\title{
AUTOMATED OPTIMIZATION OF STEEL REINFORCEMENT IN RC BUILDING FRAMES USING BIM AND HYBRID GA
}

\author{
Jack C.P. Cheng ${ }^{1}$, and Mohit Mangal ${ }^{2}$
}

\begin{abstract}
Design of steel reinforcement is an important and necessary task for designing reinforced concrete (RC) structures. Currently, steel reinforcement design is performed manually or semi-automatically using computer software such as ETABS, with reference to building codes. These methods are time consuming and sometimes error-prone. With the aid of advanced BIM technology, steel reinforcement design could be automated for fast, economical and error-free procedures.

This paper presents a BIM-based framework for automated optimization of steel reinforcement in RC building frame using developed three-stage hybrid genetic algorithm (GA). Optimization includes selection and alignment of steel reinforcement in RC building frame for the minimum steel reinforcement area, including longitudinal and shear/confinement steel reinforcement. The first and second stages optimize the longitudinal reinforcement while the final stage optimizes the shear/confinement steel reinforcement incorporating design code (BS8110) and buildability constraints. A three-storey RC building frame is analysed to check the applicability of the developed optimization framework and its improvement over current design approaches. The results show that the developed optimization framework can minimize the steel reinforcement area quickly. Automated 2D view of RC elements is then created to visualize the optimized steel reinforcement results.
\end{abstract}

Keywords: Building Information Modelling, Optimization, Interoperability, Steel reinforcement design, $\mathrm{RC}$ frame.

\section{INTRODUCTION}

Design of steel reinforcement is an important aspect in reinforced concrete (RC) structural design. Steel reinforcement should be provided in such a way that it is able to resist the design loads imposed on the structure during the life span, and it should be constructable, safe and economical at the same time.

Current practice involves steel reinforcement design as per enforced regional design codes, either by manual calculations or by partial automation using computers and software. Manual calculations sometimes lead to errors due to the tedious nature of the problem and the numerous calculations involved, whereas partial automation requires human input and therefore, can also lead to errors. Moreover, many possible solutions exist for the steel reinforcement area of a RC beam satisfying the design code requirement. All of these possible solutions are not checked before determining the amount of steel

1 Associate Professor, Department of Civil and Environmental Engineering, The Hong Kong University of Science and Technology, Hong Kong, China, cejcheng@ust.hk

2 Research Post Graduate, Department of Civil and Environmental Engineering, The Hong Kong University of Science and Technology, Hong Kong, China, mmangal@connect.ust.hk 
reinforcement leading to an uneconomical design. The calculation process is also time consuming.

Various researchers in the past have tried to optimize the steel reinforcement design process for RC elements. Leps and Sejnoha (2003) used the genetic algorithm (GA) to optimize the steel reinforcement design of RC beams in order to minimize the construction cost. However, they did not consider different diameter combinations for the steel reinforcement in RC design. The RC beam was also always divided into three subparts, irrespective of the loading conditions again restraining the solution in achieving global optimal solution. Saini et al. (2006) used Artificial Neural Network (ANN) to optimize steel reinforcement but output was only restrained to calculate the optimal percentage of steel reinforcement without further detailing, limiting the use of the optimization results on construction site. Moreover, all the above mentioned efforts lack full automation in providing input to the steel reinforcement optimization problem.

In the current architecture, engineering and construction (AEC) industry, a shift has been observed towards building information modelling (BIM) due to its capability to reduce cost, reduce error and improve efficiency. Therefore, developing a framework that overcomes the limitations of previous work as well as connects with the exiting BIM technology will be of significant value in the AEC industry.

The objective of this paper is to develop a fast, automated and error free BIM integrated optimization framework using the developed hybrid GA based optimization algorithm to perform steel reinforcement design according to the regional design code. In a typical structural frame, beams and columns are the most fundamental and commonly used structural component types. Therefore, beam and column design is considered in the current framework to check the performance of the developed optimization framework.

\section{The Proposed Automated BIM Based RC Frame STEEL REINFORCEMENT OPTIMIZATION FRAMEWORK}

The structure of the proposed automated BIM based framework for steel reinforcement optimization is explained in this section. As described in Figure 1, the framework consists of four modules: (1) BIM Model Extraction, (2) Structural Analysis, (3) Reinforcement Calculation, and (4) Reinforcement Optimization.

- BIM Model Extraction: A BIM model contains all the functional (e.g., loading and end support information) and physical (e.g., geometric information) characteristics required for calculation of steel reinforcement. Information in the BIM model is extracted for further steel reinforcement optimization calculation.

- Structural Analysis: The extracted information from the BIM model is then imported into a structural analysis software. The design bending moment and shear force are calculated for the imported RC beam. Safety factors are also considered during calculation as prescribed by the relevant design codes. The calculated bending moment and shear force results are saved for further steel reinforcement optimization calculation.

- Steel Reinforcement Calculation: The steel reinforcement requirement is then calculated considering the results of the structural analysis and other conditions stipulated in the regional design code. Detailed information about various types of steel reinforcements for RC beams and RC columns are given in Section 3 with brief discussion of design codes. 
- Steel Reinforcement Optimization: Provided steel reinforcement is then calculated on the basis of the outcome of the steel reinforcement requirement and other conditions stipulated in the regional design code. Problems faced on site during rebar placement is also considered while calculating the provided steel reinforcement.

First two modules of the framework are straight forward and require no explanation. The third and fourth module are explained in Section 3 and Section 4, respectively.

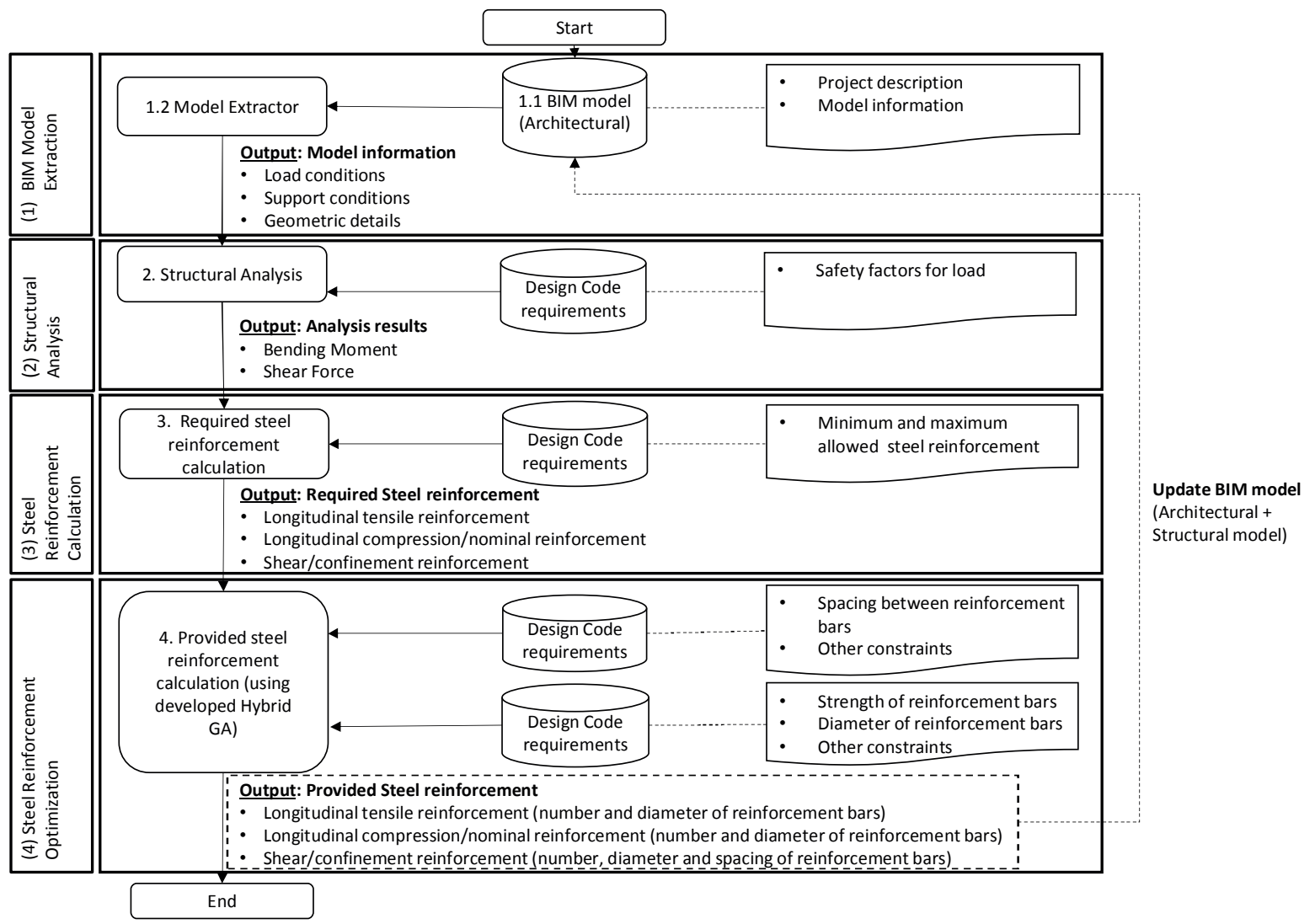

Figure 1: The proposed automated BIM based optimization framework

\section{STEEL REINFORCEMENT CALCULATION}

The variables considered during the $\mathrm{RC}$ member (beam or column) design are similar across all the design codes in different regions. The considered variables in order of calculation are (1) area of tensile reinforcement (As), (2) area of compression reinforcement (As'), and (3) cross-sectional shear area of links at the neutral axis at a section (Asv), which in turn depend on many factors, as described in Section 4.1.

Different regions have different design codes for RC design. Some of them has separate code for steel rebar properties. For example, both BS8110 and BS4449 are used in the UK and Hong Kong. BS8110 deals with the minimum required steel reinforcement depending on the building data. The building data include loading conditions, support conditions and geometrical information for all $\mathrm{RC}$ members in a given building. The required building data can be extracted from BIM models automatically using application programming interface (API). BS4449 deals with properties of the rebar such as yield strength, flexural strength and allowed diameters. However, the developed optimization tool can be modified to account for user specific rebar detail (e.g. preferred number or diameters of steel rebar). 


\section{Formulation of STEEl ReINFORCEMENT Optimization Problem}

\subsection{Definition of Variables}

\subsubsection{Longitudinal Reinforcement Area for RC Beam}

The provided tensile steel reinforcement (As) is the total cross-sectional area of tensile steel rebar provided at a section, which can be calculated as:

$$
\mathrm{A}_{s}=\sum_{1}^{t} \mathrm{n}_{i} \pi d_{i}^{2} / 4
$$

where $d i$ is the selected tensile rebar diameter from BS4449, ni is total number of tensile rebar of type $i$, and $t$ is the different types of tensile rebar. The total number of rebar depends on BS8110.

From the above, there are two variables to be considered for tensile rebar, which are (1) number of rebar, and (2) different diameter combination of rebar. Similar to provided tensile reinforcement, the provided compressive/nominal steel reinforcement (As') will have two variables to be considered, which are (1) number of rebar, and (2) different diameter combination of rebar.

\subsubsection{Shear Reinforcement Area for RC Beam}

Shear steel reinforcement (Asv) is a function of steel reinforcement links in a particular stirrup, and the cross-sectional area of each shear reinforcement link in that stirrup, as illustrated in Figure 2. However, total shear steel reinforcement area is calculated by summing all the cross-section area of individual stirrups as calculated below:

$$
\sum \mathrm{A}_{s v}=\sum_{i=1}^{v} \frac{l_{i}}{S v_{i}}\left(\mathrm{~b}_{i} \pi d_{i}{ }^{2} / 4\right)
$$

As shown in Figure 2 and Equation 2, there are four variables in each subsection i, namely (1) shear spacing between two stirrups $\left(S_{V I}\right)$, (2) length of subsection i $\left(I_{i}\right)$, (3) number of shear reinforcement links in each stirrup $\left(b_{i}\right)$, and (4) diameter of shear reinforcement links $(d i)$. Therefore, for at least three subsections, each with four variables, there are at least 12 variables to be considered for simplest case of a simply supported RC beam.

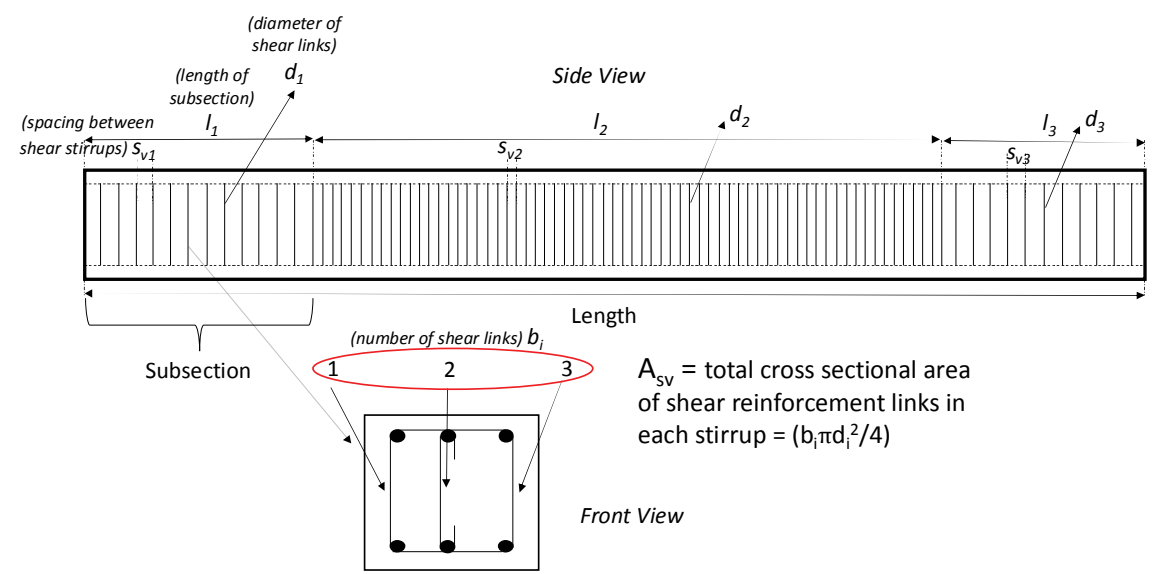

Figure 2: Different attributes for shear steel reinforcement calculation for RC beam 


\subsubsection{Objective Function for RC Beam}

It can be inferred that the total steel reinforcement area will be the sum of the longitudinal tensile steel reinforcement (As), longitudinal compression/nominal steel reinforcement $\left(A s^{\prime}\right)$, and shear steel reinforcement (Asv), i.e.

$$
\operatorname{Obj} \_ \text {func }\left(\mathrm{A}_{s}, A_{s}{ }^{\prime}, A_{s v}\right)=\mathrm{A}_{s}+A_{s}{ }^{\prime}+\sum\left(A_{s v}\right)
$$

Our objective is to minimize the objective function having at least 16 variables (2 variables for (As), 2 variables for (As'), and 12 variables for (Asv)).

\subsubsection{Objective Function for RC Column}

Similar to RC beam, the objective function of RC column will be the sum of the longitudinal tensile steel reinforcement (As), longitudinal compression steel reinforcement (Asc), and confinement steel reinforcement (Asv) i.e.

$$
\operatorname{Obj\_ func}\left(\mathrm{A}_{s}, A_{s c}, A_{s v}\right)=\mathrm{A}_{s}+A_{s c}+A_{s v}
$$

where both longitudinal tensile reinforcement (As) and longitudinal compressive rebar (Asc) have two variables to be considered, which are (1) number of rebar, and (2) different diameter combination of rebar. Although the number of variables for longitudinal reinforcement for $\mathrm{RC}$ column is similar to $\mathrm{RC}$ beam, the concepts involved in calculating the longitudinal reinforcement are entirely different.

Containment links (Asv) are also provided to hold the compressive longitudinal steel reinforcement bars in place. Containment links are provided uniformly for the whole length of RC column. Containment steel reinforcement has three variables to be considered, which are (1) number of links in each stirrup (b), (2) diameter of link (d), and (3) spacing between two stirrups (Svi). (Refer to Figure 2 for variable's notation.) Our objective is to minimize the objective function having at least seven variables (two variables for (As), two variables for (Asc), and three variables for (Asv))

The factors governing the considered variables in the developed objective function for $\mathrm{RC}$ beam and $\mathrm{RC}$ column in turn depends on building data mentioned in Section 3. The building data are extracted automatically from BIM models through the developed API.

\subsection{Penalty Function}

Steel reinforcement detailing is not only a matter of strength and cost but also a matter of constructability. A steel reinforcement detailing cannot be of optimum reinforcement area (or volume) if it is difficult to implement it on site. Three major problems are generally encountered during implementation of steel rebar design on site as discussed below.

- Number of steel rebar: The more the number of rebar, the more difficult it is to place them on site. Sometimes, concrete does not flow smoothly between rebar due to less available space between rebar. Therefore, an exterior penalty function (Coello 2002) is introduced in the objective function to control the number of rebar.

- Maximum diameter of steel rebar: As the rebar diameter increases, it become more difficult to bend the steel bars into different angles and shapes, making it a tedious job during construction. Moreover, large diameter rebar is not readily available. Therefore, a penalty function was also introduced for rebar with diameter $>25 \mathrm{~mm}$.

- Different diameter combinations of steel rebar: It is tedious to keep track of correct diameter and position of rebar if many different diameters are used in detailing. 
Hence, it was decided to keep a maximum of three different diameter combination for longitudinal rebar. No combination is considered for shear/confinement reinforcement in any subsection of RC element (Figure 2)

\section{Solving The SteEl ReINForCEMENT OPtimization Problem USING HYBRID GENETIC ALGORITHM}

\subsection{Introduction to Optimization Algorithms}

Optimization of the provided steel reinforcement depends on a minimum of 16 variables (or 7 variables for RC column) (Section 4.1.3 or 4.1.4), thus having more than a million possible combinations. Hence, a powerful yet reliable technique is required to arrive at an optimal solution within a reasonable amount of time.

Several heuristic algorithms have been developed to tackle the above types of NP-Hard problems. Some commonly used heuristic algorithms are Particle Swarm Optimization (PSO) (Eberhart and Kennedy 1995), Ant Colony Optimization (ACO) (Dorigo et al. 1996) and Genetic Algorithm (GA) (Goldberg and Holland 1988). The hybrid GA has been developed for this study as described in Section 5.2.

\subsection{Optimization Technique for the Current Problem}

Hybrid GA was developed to overcome the shortcomings of GA such as considering the different diameter combinations of steel reinforcement bars, compliance of the design codes, constructability issues faced on construction sites, low frequency of the optimum solutions and fitness of the optimum solution. Design code constraints were built-in while developing the hybrid GA in order to comply with the requirements of design codes and penalty functions were considered while incorporating the objective function in hybrid GA. Local search using Hooke and Jeeves (1961) was included in each generation to increase the frequency and quality of optimal solution. The whole hybrid GA based optimization process is shown in Figure 3.

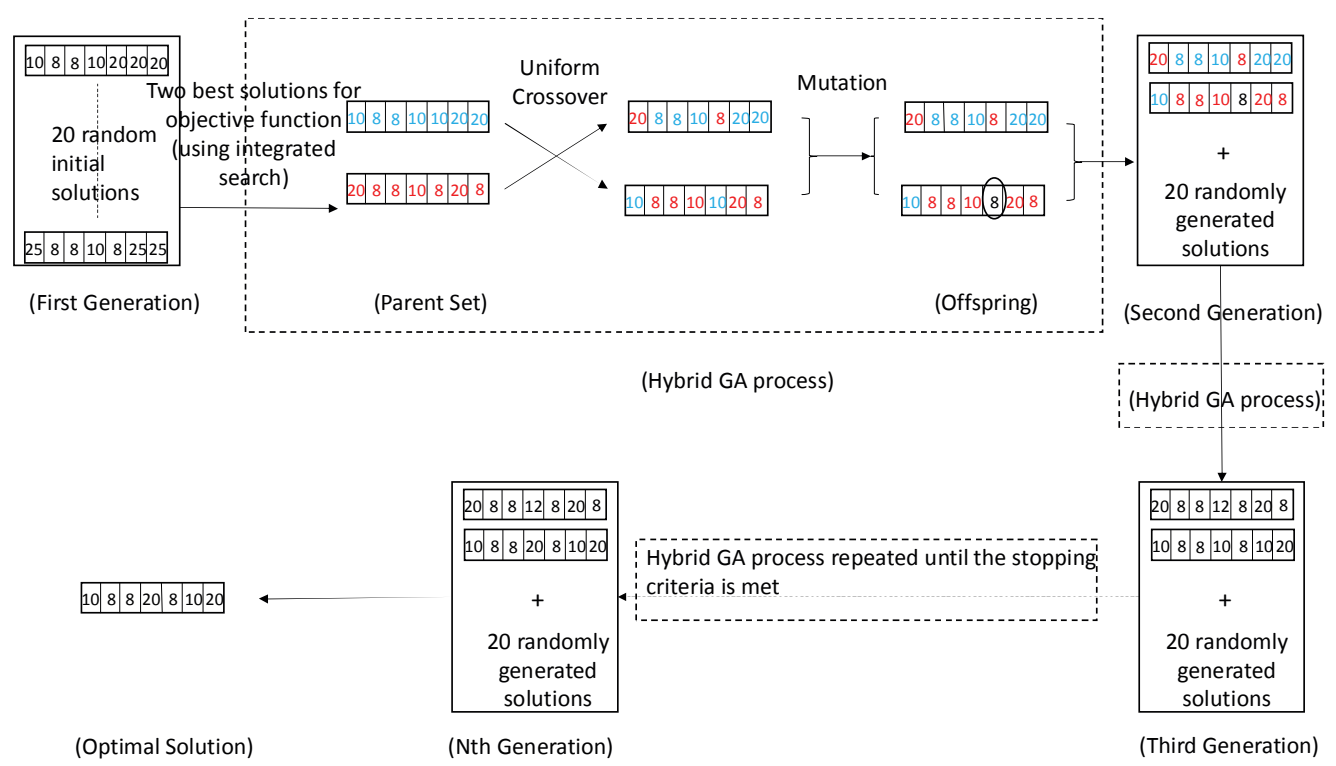

Figure 3: The developed hybrid GA for RC beam reinforcement optimization 
Stopping Criteria: It is not fruitful to repeat the generation process for a maximum of 500 generations if results within desired thresholds (e.g., difference $<1 \%$ ) have been achieved or no improvement has been recorded in the subsequent generations (e.g., 50 generations) before reaching 500 generations. Therefore, necessary and sufficient condition was applied to achieve optimal solution in least amount of time.

\section{ILLUSTRATIVE EXAMPLES}

\subsection{Illustrative Example of RC Beam}

RC beam of 6-meter length was considered to evaluate the efficiency of the developed BIM based automated steel reinforcement design framework. Uniform dead load (DL) and live load (LL) of different magnitudes was then applied on the beam (Figure 4). Developed BIM-based steel reinforcement optimization framework tool is shown in Figure 5(a)

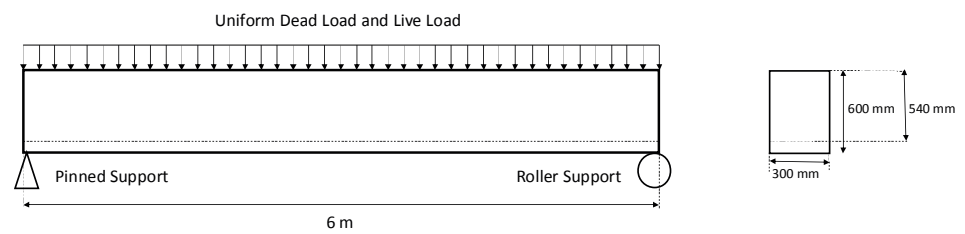

Figure 4: Geometric information for the considered simply supported RC beam

It can be inferred from Table 1 that the developed algorithm provides more optimum results as compared to other existing software (e.g., difference between required and provided reinforcement is only $0.004 \%$ for $\mathrm{DL}=15 \mathrm{KN} / \mathrm{m}$ and $\mathrm{LL}=60 \mathrm{KN} / \mathrm{m}$ ). The average run time and frequency of optimum solution were also noted for 10 independent runs and it can be inferred that developed algorithm provides fast and consistent results every time. Incorporation of penalty functions also helped to restrained number, maximum diameter, and combination of different diameter of rebars in the provided steel reinforcement. Restrained number of rebar, maximum diameter of rebar and combination of different rebar diameter facilitate smooth flow of concrete, and ease the process of rebar placement on construction sites.

Table 1: Provided Longitudinal Tensile Reinforcement Comparison

\begin{tabular}{|c|c|c|c|c|c|c|c|}
\hline \multirow{3}{*}{$\begin{array}{l}\text { Loading } \\
\text { condition }\end{array}$} & \multirow{3}{*}{\multicolumn{2}{|c|}{$\begin{array}{l}\text { Minimum } \\
\text { required rebar } \\
\text { area (As) as } \\
\text { per BS8110 } \\
\left(\mathrm{mm}^{2}\right)\end{array}$}} & \multicolumn{4}{|c|}{ Provided rebar area (As) (number and diameter of rebar) } & \multirow{3}{*}{$\begin{array}{c}\text { Avg. } \\
\text { run } \\
\text { time } \\
(\mathrm{ms})\end{array}$} \\
\hline & & & \multirow{2}{*}{$\begin{array}{c}\text { CSI } \\
\text { ETABS }\end{array}$} & \multirow{2}{*}{$\begin{array}{c}\text { Autodesk } \\
\text { RSAP }\end{array}$} & \multicolumn{2}{|c|}{ Developed optimization algorithm } & \\
\hline & & & & & No penalties & With penalties & \\
\hline $\begin{aligned} \mathrm{DL} & =10 \mathrm{~K} \\
\mathrm{LL} & =10 \mathrm{~K}\end{aligned}$ & & 816.93 & $\begin{array}{c}1206 \\
(6 \varnothing 16)\end{array}$ & $942(3 \varnothing 20)$ & 817.6 (5 bars) & $\begin{array}{c}819.96 \\
(1 \varnothing 10,1 \varnothing 12,2 \varnothing 20)\end{array}$ & $10-12$ \\
\hline $\begin{aligned} \mathrm{DL} & =15 \mathrm{~K} \\
\mathrm{LL} & =15 \mathrm{~K}\end{aligned}$ & $/ / \mathrm{m}$ & 1199.96 & $\begin{array}{c}1885 \\
(6 \varnothing 20)\end{array}$ & $\begin{array}{c}1256 \\
(4 \varnothing 20)\end{array}$ & $\begin{array}{l}1200.09(9 \\
\text { bars })\end{array}$ & $\begin{array}{c}1207.16 \\
(2 \varnothing 16,1 \varnothing 20,2 \varnothing 25)\end{array}$ & $9-12$ \\
\hline $\begin{aligned} \mathrm{DL} & =15 \mathrm{~K} \\
\mathrm{LL} & =39 \mathrm{~K}\end{aligned}$ & $\begin{array}{l}\mathrm{m}, \\
\mathrm{m}\end{array}$ & 2390.79 & $\begin{array}{c}3770 \\
(3 \varnothing 40)\end{array}$ & $\begin{array}{c}2513 \\
(8 \varnothing 20)\end{array}$ & $\begin{array}{c}2391.5(6 \\
\text { types of bars) }\end{array}$ & $\begin{array}{c}2395.46 \\
(2 \varnothing 10,4 \varnothing 20,2 \varnothing 25)\end{array}$ & $68-82$ \\
\hline $\begin{array}{l}\mathrm{DL}=15 \mathrm{~K} \\
\mathrm{LL}=60 \mathrm{~K}\end{array}$ & $\begin{array}{l}\mathrm{N} / \mathrm{m} \\
\mathrm{J} / \mathrm{m}\end{array}$ & 3195.66 & $\begin{array}{c}6283 \\
(5 \varnothing 40)\end{array}$ & $\begin{array}{c}3455 \\
(11 \varnothing 20)\end{array}$ & $\begin{array}{c}3195.78(\max \\
\varnothing=40)\end{array}$ & $\begin{array}{c}3195.78 \\
(1 \varnothing 12,2 \varnothing 20,5 \varnothing 25)\end{array}$ & 70-74 \\
\hline
\end{tabular}




\subsection{Illustrative Example of RC Frame}

$\mathrm{RC}$ frame as a whole is considered to evaluate the efficiency of the developed framework at the entire frame level. The considered fixed end $\mathrm{RC}$ frame is given in Figure 5(b) and automated 2D output for one of the RC column is given in Figure 5(c).

\section{CONCLUSION}

In this paper, we proposed a BIM-based automated optimization framework for steel reinforcement using the developed hybrid GA. The objective was to provide minimum steel rebar area satisfying the design codes and constructability requirements. The formulated objective function allowed us to consider all the variables affecting the real life design and construction process of steel rebar. Moreover, the developed hybrid GA provided fast and consistent results even for real life situations. The developed BIM based framework provides full automation and interoperability to achieve fast, optimized and reliable results. Future work will include the development of objective function for RC slabs in order to include it in developed BIM based optimization framework.
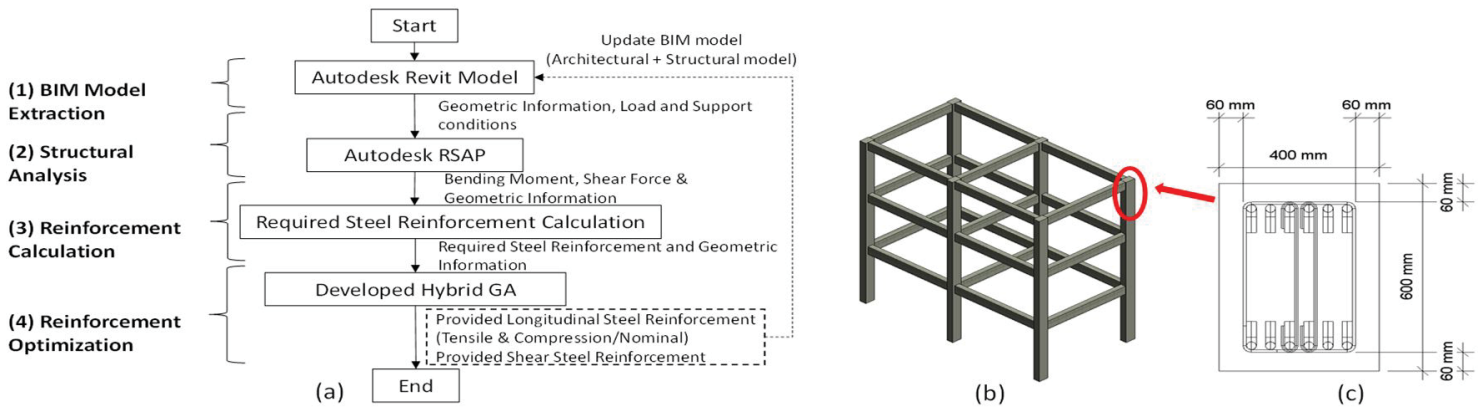

Figure 5: (a) BIM-based steel reinforcement optimization framework tool, (b) 03Floor fixed end RC frame, (c) 2D view of the optimized rebar for a RC column

\section{REFERENCES}

Coello, C.A.C. (2002). Theoretical and numerical constraint-handling techniques used with evolutionary algorithms: a survey of the state of the art. Computer methods in applied mechanics and engineering, 191 (11), 1245-1287.

Dorigo, M., Maniezzo, V. and Colorni, A. (1996). Ant system: optimization by a colony of cooperating agents. Systems, Man, and Cybernetics, Part B: Cybernetics, IEEE Transactions on, 26 (1), 29-41.

Eberhart, R.C and Kennedy, J. (1995) A new optimizer using particle swarm theory. Proceedings of the sixth international symposium on micro machine and human science, 1995. New York, NY, 39-43.

Goldberg, D.E and Holland, J.H. (1988). Genetic algorithms and machine learning. Machine learning, 3 (2), 95-99.

Hooke, R. and Jeeves, T.A. (1961). Direct search solution of numerical and statistical problems. Journal of the ACM (JACM), 8 (2), 212-229.

Leps, M. and Sejnoha, M. (2003). New approach to optimization of reinforced concrete beams. Computers \& structures, 81 (18), 1957-1966.

Saini, B., Sehgal, V. and Gambhir, M. (2006). Genetically optimized artificial neural network based optimum design of singly and doubly reinforced concrete beams. Asian Journal of Civil Engineering (Building And Housing), 7 (6), 603-619. 